\title{
Korean Adolescents' Experience of Yoga Class: 'Healthy Habits Beyond Exercise"
}

\author{
Lee, Ji Hye ${ }^{1}$ Chae, Sun $\mathrm{Mi}^{2}$ \\ ${ }^{1}$ Graduate Student, College of Nursing, Seoul National University, Seoul \\ ${ }^{2}$ Associate Professor, College of Nursing, Seoul National University, Seoul, Korea
}

\begin{abstract}
Purpose: This study was designed to explore adolescents' experience with yoga class in South Korea. Methods: Qualitative data were collected by focus group interviews from February to March 2014. Eleven adolescents who experienced yoga class were recruited from two different schools. The interview questions investigated adolescents' experience with yoga regarding expectations before yoga class, positive changes after yoga, and advice for future yoga classes. Results: Three primary themes from the qualitative content analysis include 1) motivation to join a yoga class, 2) perceived benefits after class and 3) suggestions for school-based yoga. We found that high school students had intrinsic and extrinsic motivations to join yoga classes, and the perceived benefits included physical, psychological, cognitive and social aspects. The students also indicated the need for support by person, yoga with fun and information, yoga tailored by individual goal, simple and easy class. Conclusion: These results suggest that yoga could be an appropriate intervention for holistic health care, and school-based yoga should be applied by focusing on the various situational needs of adolescents'. Furthermore, when yoga leads to healthy habits compared to just simple exercise, a balanced development of adolescents can be achieved.
\end{abstract}

Key Words: Yoga, Adolescent, School health service, Health behavior, Focus groups

\section{INTRODUCTION}

Yoga is a three thousand year old wisdom tradition which is a comprehensive mind-body intervention, such as postures (asana), regulation of breathing (pranayama), relaxation, and meditation, that develops self-observation without judgment, with the ultimate goal of optimizing human life from a physical, emotional, cognitive, and social aspect. ${ }^{1)}$ The practice of yoga has become increasingly common not only in the East but also in the West. ${ }^{2)}$ According to the 2012 National Health Interview Survey which included complementary health approaches by Americans, $8.4 \%$ of adults practiced yoga in the previous year which is an increase from $6.1 \%$ in $2007 .{ }^{3,4)}$ The 2007 survey also found that 2.1\%(or approximately 1.5 million) children under 18 years of age practiced yoga in the previous year.' Indeed, yoga's popularity could be due to in large part its ability to produce changes in the body and mind based on self-care approaches in daily life, not providing by health professionals. ${ }^{3)}$ In western industrialized cultures, yoga is typically regarded as physical exercise, although yoga's roots are deeply philosophical and spiritual. ${ }^{6}$ )

Studies have shown that the practice of yoga reduces stress and negative feelings, maintains peace and happiness, improves the concentration and flexibility of the body, relives pain and helps with weight control in adults with various health conditions such as cancer, chronic back pain, obesity, type 2 diabetes, and risk of cardiovascular diseases. ${ }^{7-11)}$ Although only a few studies on yoga in adolescents have been done, several studies have shown similar outcomes in adults. ${ }^{12)}$ Remarkably, some studies have reported that the practice of yoga helps to reduce stress related to academic performance, increases self-esteem and self-regulation and promotes healthy behaviors in adolescents. ${ }^{12-16)}$

High school students in Korea are a health risk group under a lot of stress from preparing for the scholastic aptitude test or finding jobs, and they have the risk of low physical activity and irregular eating habits as well as a lack of sleep and high health risk behaviors such as smoking, drinking alcohol. ${ }^{17)}$ The choice of an unhealthy life

Corresponding author: Lee, Ji Hye

College of Nursing, Seoul National University, 103 Daehak-ro, Jongno-gu, Seoul 110-799, Korea

Tel: +82-2-740-8851, Fax: +82-2-765-4103, E-mail: ljh33333@snu.ac.kr

투고일 2014년 8월 14일 / 심사완료일 2014년 9월 19일 / 게재확정일 2014년 10월 2일 
style made by many adolescents has resulted in chronic conditions such as cardiovascular diseases, cancer, obesity and type 2 diabetes after the transition to adulthood. ${ }^{18)}$ For adolescents facing a developmental crisis, school-based yoga could be an appropriate intervention to promote healthy behaviors and to improve the general health of students in their daily school life. ${ }^{14-16,19)}$ School is an important environment in an adolescent's life, and bringing yoga into a school environment has unique challenges and opportunities. ${ }^{13,19)}$ Therefore, in order to develop a desirable and feasible yoga class, it is important to listen to the suggestions of students on an appropriate school-based yoga class. ${ }^{12)}$

In addition to the health benefits quantified in yoga intervention trials, a limited number of qualitative studies have described the health-related outcomes not readily captured by conventional instruments. ${ }^{12)}$ The practice of yoga is a complex holistic intervention in which each student can perceive peculiar changes and improvements. ${ }^{1)}$ Qualitative research, which collects data on the unique experiences of study participants, is the perfect approach for exploring each student's change in perception and improvement in body and enhancing scientific knowledge beyond what can be measured quantitatively. ${ }^{12)}$

Knowing why students start to practice yoga, why they continue, and what class they prefer could shed light on the factors that appeal to novices and regular practitioners, with important implications in making yoga a longterm lifestyle choice. ${ }^{20)}$ To date, a few studies have examined why adolescents practice yoga and what benefits they perceive from practicing yoga using qualitative methods. Hence, the overall purpose of this qualitative study was to explore the motivation to start practicing yoga, the perceived benefits after yoga class, and suggestions for an appropriate yoga class as described by high school students who had experienced yoga class.

\section{METHODS}

\section{Research Design}

A qualitative research design using focus group interviews was adopted for this study. The focus group method is a powerful research tool to bring out the views and elicit adolescents' perspectives on a variety of issues related to health and wellness. ${ }^{21)}$ Unlike individual interview or observation, a focus group interview provides an opportunity to use interaction data resulting from a discussion among adolescents and clarifies their perceptions. $^{22)}$

\section{Preparation of Researchers}

Two researchers in this study have had experiences with qualitative research using focus group interviews with adolescents. Additionally, the first author listened to lectures on how to perform qualitative research and participated in several workshops organized by the Korean Association for Qualitative Research. In addition, this study was done after obtaining advice on qualitative content analysis from professors in qualitative research. Moreover, the first author received one month of yoga training in India through a support program for shortterm study abroad and is currently talking a yoga instructor course in Korea.

\section{Ethical Considerations}

The study was reviewed and approved by the researchers' institutional review board (IRB No. 1402/001012). After providing information regarding the purpose and method of this study, written informed consent was obtained from the adolescents and their parents prior to participating in the study. All collected data were anonymous. The names of the participants were not mentioned. The confidentiality of the participants was assured throughout the study by using only interviewee identification numbers such as A1 in all recordings and documents. The voice recording and transcript data were kept in a locked folder managed by computers which were owned by the researchers.

\section{Recruitment of Participants}

Eleven adolescent participants who participated in school- or community-based yoga classes more than once were recruited for three groups. Recruitment for interviews was conducted through individual contact and with the school nurse using convenience sampling from two high schools, in which one was a general high school leading to college and the other a vocational high school leading to employment at a company. Because two school was coeducational schools, there's no limitation to the gender selection in recruiting of participants. The decision to recruit a new group was done at the same time with an analytics process, and data collection was completed when the saturation point was reached. Despite the common contents already extracted after the first group and the second group interview, the third group was conducted interviews with the vocational high school students to ensure the variety of participants. 


\section{Data Collection}

Focus group interviews were conducted from February to March, 2014. Selected participants were contacted 1 week ahead of the interview, and the time and place for the interview were arranged. The interview was conducted in a seminar room near the high school and in their high school health education room which was a quiet place to focus on the interview. Because all interview participants were adolescents, their safety was considered when transporting them to the interview place. For students interviewed at a location not in their school, their transportation expenses were paid for. The interviews lasted from at least 60 minutes up to 90 minutes. All focus group interviews were audio-recorded and moderated by one of the authors.

Interview questions developed by the researcher based on the research purpose consisted of five parts: warming up to discussion, expectations before the class to derive the motivation for taking a yoga class, experiences with yoga to derive the perceived benefits after yoga, advice for future yoga classes and closing statement (Table 1). Additional data including their general characteristics, type of yoga class participating in, whether they want to participate in a yoga class again, the reason for taking a yoga class, and the current degree of stress and fatigue were also collected before the interview with a brief open-ended questionnaire. In addition, the moderator took notes to record personal responses and the participants' feelings.

\section{Data Analysis}

Descriptive statistics were used to delineate the dem- ographics of participants and the characteristics of the yoga classes. After the end of each interview, the voicerecordings were sent to a transcriber, a nursing student whose first language is Korean. The recordings were transcribed verbatim, and the author reviewed the transcribed data and voice recordings for accuracy. The complete transcriptions were examined by qualitative content analysis with counting code. ${ }^{23)}$ Conventional content analysis is a qualitative research methodology used to analyze data for the purpose of condensing, describing, and ultimately categorizing phenomenon on the basis of the research questions without specific philosophical background and theory. ${ }^{24)}$ Qualitative content analysis requires an analytical process of seven steps, including formulating the research questions, selecting the sample to be analyzed, defining the categories to be applied, outlining the coding process and training the coder, implementing the coding process, determining trustworthiness, and analyzing the results of the coding process. ${ }^{25)}$ First, we repeatedly read the transcriptions to understand the details and to find meaningful words, phrases, sentences, and then, the contents were organized into sub-categories and categories, and the primary themes were in accordance with the research questions.

\section{Rigor}

In this study, four evaluation criteria including credibility, fittingness, auditability and confirmability were used to examine the trustworthiness of the qualitative study. ${ }^{26)}$ First, to ensure credibility as an internal validity, three strategies were used: perfect and immediate transcription after each interview for accurate data collec-

Table 1. Interview Questions

\begin{tabular}{|c|c|}
\hline Section & Questions \\
\hline Warming up & $\begin{array}{l}\text { Freely talk about your experience with participating in yoga classes. } \\
\text { - Tell me about any regrets you have about any previous yoga classes. }\end{array}$ \\
\hline $\begin{array}{l}\text { Expectations before yoga class : } \\
\text { Motivations for joining yoga class } \\
\text { (Theme } 1 . \text { derived) }\end{array}$ & $\begin{array}{l}\text { Who recommended to you taking a yoga class? } \\
\text { - What were your expectations when you first joined the yoga class? }\end{array}$ \\
\hline $\begin{array}{l}\text { Experience of yoga class: } \\
\text { Perceived benefits after yoga class } \\
\text { (Theme } 2 . \text { derived) }\end{array}$ & $\begin{array}{l}\text { - Let us discuss the effects of yoga practice on high school students. } \\
\text { - What changes have you experienced in your body and mind after taking yoga class? } \\
\text { - What is the most stressful thing in your daily school life? }\end{array}$ \\
\hline $\begin{array}{l}\text { Advice for future yoga classes: } \\
\text { Suggestions for a school-based } \\
\text { yoga class (Theme } 3 \text {. derived) }\end{array}$ & $\begin{array}{l}\text { - Please give us your best suggestions for a school-based yoga class. } \\
\text { - What's the strategies for promoting participation in the yoga class } \\
\text { - Please recommend a method for maintaining yoga in your daily life }\end{array}$ \\
\hline Closing statements & $\begin{array}{l}\text { Are there any other thoughts about yoga that you would like to share with us? } \\
\text { - Thank you for your time. If you have any questions, please contact me at any time. }\end{array}$ \\
\hline
\end{tabular}


tion, member check, and peer debriefing for accurate analysis. In addition, agreement related to the content was achieved following two independent reviews of the translated data into English by a person fluent in both Korean and English. For fittingness as an external validity, two nursing scholars (a school nurse, a child health nursing professor), and one yoga expert who received a $\mathrm{PhD}$ in yoga therapy read the findings of this study and commented on the fittingness from the results of the qualitative content analysis. Additionally, we presented in detail the demographic data of the participants including their age, gender, and grade and the characteristics of the yoga class they participated in. For auditability as reliability, the researchers reviewed the field notes and memos as an audit trail. Toward that end, participant quotes are presented together with the findings and also shown in the results table. Furthermore, two experienced qualitative researchers reviewed the audit trail and explored decisions regarding the data analysis. For confirmability as objectivity, threats to neutrality including researcher bias were minimized by increasing access to the raw data and by peer review.

\section{RESULTS}

\section{Sample Characteristics}

General characteristics and class types are shown in Table 2. The three groups consisted of $3 \sim 4$ students, and there was some diversity in age, grade, and when the first yoga class was taken. Most students were girls except for one boy, and three students participated in a community-based yoga class while the rest in schoolbased programs. The school-based yoga programs were
8 weeks to 16 weeks length. The average stress levels measured with a 10 point Likert scale were 5.1 points. The students' body mass index was calculated from their height and weight, and as a result, two girls were obese. However, one of the two obese girls expressed that her health was good. Additionally, most of the normal weight group (8 out of 9) answered they wanted to lose weight. However, one male student answered he wanted to gain weight in the normal weight group. The misconception about weight and health perception was identified, and there was a definite difference between the girls and boys. Lastly, students answered whether they want to participate in yoga classes, again. In addition, there were some differences between the girls and boy. Only one boy answered that he did not want to join yoga class again because he wanted a more active exercise than yoga.

\section{Primary Themes}

Three primary themes emerged from the data analysis. A detailed description of each theme follows. The researchers abstracted 10 categories, with 39 sub-categories that fell under the three primary themes: 1 ) motivations for joining a yoga class 2) perceived benefits after the yoga class, and 3) suggestions for a school-based yoga class.

\section{Theme 1: Motivations for joining a yoga class}

Research question 1 examined the expectations before the yoga class. Theme 1 induced by this question was the motivation for joining a yoga class. Two categories emerged from the qualitative data, and the participants had intrinsic and extrinsic motivations prior to at-

Table 2. General Characteristics of the Participants

\begin{tabular}{|c|c|c|c|c|c|c|c|c|c|c|c|c|}
\hline ID & Gender & Age & Grade & $\begin{array}{l}\text { Type of } \\
\text { school }\end{array}$ & $\begin{array}{l}\text { First } \\
\text { Yoga } \\
\text { class }\end{array}$ & $\begin{array}{c}\text { Location } \\
\text { of Yoga } \\
\text { class }\end{array}$ & $\begin{array}{l}\text { Will join a } \\
\text { Yoga class } \\
\text { again? }\end{array}$ & $\begin{array}{l}\text { Body } \\
\text { Mass } \\
\text { Index }\end{array}$ & $\begin{array}{l}\text { Weight } \\
\text { group }\end{array}$ & $\begin{array}{c}\text { Wants to } \\
\text { gain/lose } \\
\text { weight }\end{array}$ & $\begin{array}{c}\text { Perception } \\
\text { of } \\
\text { health }\end{array}$ & $\begin{array}{c}\text { Stress } \\
(0 \sim 10)^{*}\end{array}$ \\
\hline A1 & $\mathrm{F}$ & 16 & 10th & General & 10th & School & Yes & 21.8 & Normal & Lose & Good & 3 \\
\hline $\mathrm{A} 2$ & M & 16 & 10th & General & 8th & School & No & 18.9 & Normal & Gain & Good & 7 \\
\hline A3 & $\mathrm{F}$ & 16 & 10th & General & 6th & School & Yes & 25.9 & Obese & Lose & $\mathrm{Bad}$ & 8 \\
\hline $\mathrm{A} 4$ & $\mathrm{~F}$ & 16 & 10th & General & 10th & School & Yes & 21.3 & Normal & Lose & $\mathrm{Bad}$ & 7 \\
\hline B5 & $\mathrm{F}$ & 16 & 11th & General & 10th & School & Yes & 19.0 & Normal & Lose & $\mathrm{Bad}$ & 6 \\
\hline B6 & $\mathrm{F}$ & 16 & 11th & General & 8 th & School & Yes & 22.8 & Normal & Lose & Moderate & 4 \\
\hline B7 & $\mathrm{F}$ & 16 & 11th & General & 9th & Community & Yes & 20.0 & Normal & Lose & Bad & 2 \\
\hline $\mathrm{C} 8$ & $\mathrm{~F}$ & 17 & 12th & Vocational & 5 th & School & Yes & 18.4 & Normal & Lose & $\mathrm{Bad}$ & 6 \\
\hline C9 & $\mathrm{F}$ & 17 & 12th & Vocational & 8th & Community & Yes & 27.6 & Obese & Lose & Good & 4 \\
\hline C10 & $\mathrm{F}$ & 17 & 12th & Vocational & 8th & Community & Yes & 18.7 & Normal & Lose & Moderate & 4 \\
\hline C11 & $\mathrm{F}$ & 17 & 12th & Vocational & 11th & School & Yes & 20.0 & Normal & Lose & Moderate & 5 \\
\hline
\end{tabular}

*(0 10): Not at all-Very much so; Mean stress level: 5.1. 
tending yoga class. The representative quotations showing the motivations for joining a yoga class are presented in Table 3. Most participants (9 out of 11) reported exercise for their body regarding weight control, alleviation of pain, body shape and posture as their intrinsic motivation. Also, a small number of students (2 out of 11) reported exercise for their mind in terms of reducing stress, and one student's motivation was for a positive impact on their studying because yoga and meditation are less tiring than that of other exercises as their intrinsic motivation. On the other hand, two out of eleven participants mentioned that yoga class was a way to meet new friends as their extrinsic motivation. Additionally, four students reported that, yoga class as exercise was recommended by others including mother, class teacher, gym teacher, and private health trainer as their extrinsic motivation.

\section{Theme 2: Perceived benefits after yoga class}

Theme 2 induced by the research question about the participants' experience with yoga class was the perceived benefits after yoga class consisting of four catego- ries. The representative quotations showing the perceived benefits of yoga are presented in Table 4. The subcategories for the physical benefits were weight control, improvement of flexibility, correcting body position and shape, relief of pain (such as head, shoulder, and back aches), fatigue relief, muscle relaxation and improvement in blood circulation. Participants expressed that the yoga class helped to reduce stress, increased patience and calmness, induced a deep sleep, provided refreshment and happiness in terms of psychological benefits. Moreover, the participants reported that the yoga classes offered time for self-reflection and time to recognize the possibility of positive changes, and increased their concentration on their body and yoga movement, and the yoga class had a positive impact on their academic performance providing time to refresh oneself before studying at night. These four benefits were included into the category as cognitive aspects. Lastly, some participants reported that the yoga class was a joyful activity with friends, and the yoga class helped to strengthen the intimacy with the gym teacher regarding social benefits.

Table 3. Representative Quotations of Motivations for Joining a Yoga Class

\begin{tabular}{|c|c|c|}
\hline Categories & Subcategories & Representative quotations \\
\hline \multirow[t]{3}{*}{$\begin{array}{l}\text { Intrinsic } \\
\text { motivation }\end{array}$} & $\begin{array}{l}\text { a) Exercise for } \\
\text { the body }\end{array}$ & $\begin{array}{l}\text { - "I place emphasis on the exercise part, just for weight loss." (A1) } \\
\text { - "I thought signing up for yoga.... would help alleviate my headaches." (A2) } \\
\text { - "I have scoliosis...I did ir for my back pain first." (A3) } \\
\text { • "In high school, my body has become unfit because my physical activity level is } \\
\text { low. I thought by having something to do, I would physically move more." (A4) } \\
\text { - "I started because I heard that my body shape would get better." (B2) }\end{array}$ \\
\hline & $\begin{array}{l}\text { b) Exercise for } \\
\text { the mind }\end{array}$ & $\begin{array}{l}\text { "Sitting down all day long to study puts a lot of stress on me. Physical education } \\
\text { class is very short, at only two hours a week. It was too stuffy so I applied for a } \\
\text { yoga class after school." (A3) } \\
\text {. "Other after school classes were about literature and science but there was only } \\
\text { yoga class for my mind...I simply thought that it would help because I have } \\
\text { personal stress." (A4) }\end{array}$ \\
\hline & $\begin{array}{l}\text { c) Exercise for } \\
\text { study }\end{array}$ & $\begin{array}{l}\text { "I was in a position to study, but playing soccer made me too tired and sleepy. } \\
\text { I did not want my exercise to have too much of an impact on my studies } \cdots \text { that is } \\
\text { why I chose yoga in order for me to be able to do both exercise and study. " (A2) }\end{array}$ \\
\hline \multirow[t]{2}{*}{$\begin{array}{l}\text { Extrinsic } \\
\text { motivation }\end{array}$} & $\begin{array}{l}\text { a) Exercise with } \\
\text { friends }\end{array}$ & $\begin{array}{l}\text { "I attended an international school in India for 6th grade. I just liked meeting new } \\
\text { people in yoga. I joined yoga class to meet new friends." (A3) } \\
\text { - "It was good to take a class with my friends because it is easy to give up when I } \\
\text { practice yoga alone." (A4) }\end{array}$ \\
\hline & $\begin{array}{l}\text { b) Exercise } \\
\text { recommended } \\
\text { by others }\end{array}$ & $\begin{array}{l}\text { - "My mum made me start yoga." (A2) } \\
\text { "I did it with my friend based on his recommendation. My gym and class teacher } \\
\text { also recommended saying it is good for the waist." (A3) } \\
\text { - "The doctor recommended yoga for blood circulation." (B3) } \\
\text { - "I started because a trainer in a private gym recommended yoga." (C4) }\end{array}$ \\
\hline
\end{tabular}


Table 4. Representative Quotations of Perceived Benefits after Yoga Class

\begin{tabular}{|c|c|c|}
\hline Categories & Subcategories & Representative quotations \\
\hline \multirow[t]{7}{*}{$\begin{array}{r}\text { Physical } \\
\text { aspects }\end{array}$} & a) Weight control & $\begin{array}{l}\text { - "I lost a lot of weight in my lower body."(B3) } \\
\text { • "I definitely lost a lot of weight doing yoga. About 5kg then."(C3) }\end{array}$ \\
\hline & $\begin{array}{l}\text { b) Improvement in } \\
\text { flexibility }\end{array}$ & $\begin{array}{l}\text { "I also felt like I became very flexible. I could not bend forward. After doing yoga, I } \\
\text { was able to reach down to touch my toes."(A2). }\end{array}$ \\
\hline & $\begin{array}{l}\text { c) Correct body } \\
\text { shape }\end{array}$ & $\begin{array}{l}\text { - "After yoga, I could see that my body line was better."(B3) } \\
\text { - "Yoga has a lot of straightening postures. I felt my back straighten out."(C1) }\end{array}$ \\
\hline & d) Pain relief & $\begin{array}{l}\text { - "My headaches got better at that time."(A4) } \\
\text {. "Yoga helped with my shoulder pain a lot."(C1) }\end{array}$ \\
\hline & e) Fatigue relief & $\begin{array}{l}\text { - "I liked doing yoga. It relieved my fatigue before studying at night."(A2) } \\
\text { - "Meditation relieved my fatigue although it was only for } 10 \text { minutes."(B2) }\end{array}$ \\
\hline & $\begin{array}{l}\text { f) } \text { Muscle } \\
\text { relaxation }\end{array}$ & $\begin{array}{l}\text { - "It definitely relaxes my shoulders and back muscles."(C1) } \\
\text {. "My whole body felt refreshed because my tense muscles were relaxed."(C2) }\end{array}$ \\
\hline & $\begin{array}{l}\text { g) Improvement } \\
\text { in circulation }\end{array}$ & $\begin{array}{l}\text { "I swallowed easily the next day, but now my face does not swallow in the morning. } \\
\text { I think my blood circulation is better."(B3) }\end{array}$ \\
\hline \multirow[t]{5}{*}{$\begin{array}{l}\text { Psychological } \\
\text { aspects }\end{array}$} & $\begin{array}{l}\text { a) Stress } \\
\text { reduction }\end{array}$ & $\begin{array}{l}\text { - " Doing yoga movements after school relieves my stresses."(B1) } \\
\text {. "A lot of stress from studying and preparing for college was relieved."(B2) }\end{array}$ \\
\hline & $\begin{array}{l}\text { b) Increase in } \\
\text { patience and } \\
\text { calmness }\end{array}$ & $\begin{array}{l}\text { - "I had better patience because there is a lot of holding postures in yoga. So, I do not } \\
\text { get angry easily."(B2) } \\
\text {. "My personality was more stable and calm in my everyday life."(A2) }\end{array}$ \\
\hline & c) Deep sleep & $\begin{array}{l}\text { - "I fell into a deep sleep only after } 5 \text { min. It is really amazing."(A3) } \\
\text { - "Meditation is like a really short nap; it feels like a long time."(B2) }\end{array}$ \\
\hline & d) Refreshment & $\begin{array}{l}\text {. "I feel more refreshed and that feeling persists even after yoga."(A4) } \\
\text {. "After sweating from doing yoga, I felt fresh."(C3) }\end{array}$ \\
\hline & e) Happiness & $\begin{array}{l}\text { - "I feel so happy when I come out of the shower."(C3) } \\
\text {. "There was a happy and pleasant feeling from doing yoga."(C4) }\end{array}$ \\
\hline \multirow[t]{4}{*}{$\begin{array}{l}\text { Cognitive } \\
\text { aspects }\end{array}$} & a) Self-reflection & $\begin{array}{l}\text { - "It' s a time for self- reflection."(A2) } \\
\text { - "I can think about myself. I might be able to reorganize and reflect upon myself and } \\
\text { find my inner peace like student A2 said."(A4) }\end{array}$ \\
\hline & $\begin{array}{l}\text { b) Insight of } \\
\text { possibility }\end{array}$ & $\begin{array}{l}\text { - "I know my body has changed. It shows me the possibilities."(A3) } \\
\text { - "You know how you lie down and put your feet over your head. I could not do that, } \\
\text { but after practicing, I can do it now."(C2) }\end{array}$ \\
\hline & $\begin{array}{l}\text { c) Increase of } \\
\text { concentration }\end{array}$ & $\begin{array}{l}\text {. "When meditating, I close my eyes and concentrate on my body"(B2) } \\
\text {. "I just focus on the movements without any miscellaneous thoughts."(C2) }\end{array}$ \\
\hline & $\begin{array}{l}\text { d) Academic } \\
\text { performance }\end{array}$ & $\begin{array}{l}\text { - "I am less tired because of a clear mind and I get to think deeply while meditating and } \\
\text { this helps me to study."(A3) }\end{array}$ \\
\hline \multirow[t]{2}{*}{$\begin{array}{l}\text { Social } \\
\text { aspects }\end{array}$} & $\begin{array}{l}\text { a) Joyfulness with } \\
\text { friends }\end{array}$ & $\begin{array}{l}\text { - "We did yoga with students in other class, so I got to make more friends."(A3) } \\
\text { "I did not know the students from the other classes well. But many students come } \\
\text { here. We became close by encouraging each other when we did hard movements } \\
\text { together and now we go exercise together."(B1) }\end{array}$ \\
\hline & $\begin{array}{l}\text { b) Intimacy with } \\
\text { teacher }\end{array}$ & $\begin{array}{l}\text { "I get to spend more time with the teacher than during a usual semester. So being } \\
\text { closer with the gym teacher was a positive experience."(A1) }\end{array}$ \\
\hline
\end{tabular}




\section{Theme 3: Suggestions for a school-based yoga class}

Theme 3 induced by the research question about advice for the next yoga class in the future had the findings grouped into four categories shown in Table 5. Most participants mentioned the importance of a comfortable environment to practice yoga. They suggested that the place for yoga class must be neat and clean, and warm and quiet. In addition, they expressed a desire for privacy by blocking the windows providing an atmosphere that focuses on the practice room. Some participants suggested small, short and regular classes as desirable yoga classes, and two participants suggested an affordable tuition fee rather than free tuition when students sign up for a yoga class so they would feel obligated to attend. In order to facilitate participation in the yoga class, they advised that support and encouragement from people (such as a classmate or a teacher) are essential. They also suggested that the yoga class have the following unique attributes: provide a challenge and a sense of achievement, provide a specific purpose (lose weight for girls and increase height for boys), have an attractive yoga teacher or provide a photo of celebrities' performing yoga, provide health information related to each yoga posture, and provide an individual approach according to each person's ability for practicing yoga. Finally, participants suggested the yoga class must be simple and easy to practice in daily life in the class room or while sitting on a bus, and two participant expressed that yoga should be an everyday habit for their health.

In summary, 3 primary themes evolved from the 3 research questions related to high school students' experience with yoga class. There appeared to be intrinsic and extrinsic motivations, and many of the participants expressed multi-dimensional benefits. Finally, participants were enthusiastic in offering suggestions for developing a school-based yoga class and made excellent suggestions for how a sustainable yoga class could be adapted to their adolescent life.

Table 5. Representative Quotations of Suggestions for a School-based Yoga Class

\begin{tabular}{|c|c|c|}
\hline Categories & Subcategories & Representative quotations \\
\hline \multirow[t]{3}{*}{$\begin{array}{l}\text { Comfortable } \\
\text { environment }\end{array}$} & $\begin{array}{l}\text { a) Clean } \\
\text { environment }\end{array}$ & $\begin{array}{l}\text { " A clean environment is good. The yoga mattress is too dirty to lie on. The air was } \\
\text { bad in the room. We always had to close the door in classroom because too much } \\
\text { smoke would came in if we did not close the door."(A3) }\end{array}$ \\
\hline & b) Warm place & $\begin{array}{l}\text { "Cold temperature was a barrier. I asked for more heat because warmth stimulates } \\
\text { blood circulation and sweating improves the effects of yoga. It is not very good to do } \\
\text { it in the cold."(B2) }\end{array}$ \\
\hline & $\begin{array}{l}\text { c) Quiet and } \\
\text { focused } \\
\text { atmosphere }\end{array}$ & $\begin{array}{l}\text { - "I don' t like hearing car sounds in yoga class. When I listen to nature' s sound, I } \\
\text { feel better during meditation."(B1) } \\
\text { - "You should guarantee privacy in the classroom atmosphere and block the windows } \\
\text { so that no one outside can glance through the windows."(C1) }\end{array}$ \\
\hline \multirow[t]{4}{*}{$\begin{array}{l}\text { Suitable structure } \\
\text { for yoga class }\end{array}$} & a) Small class & $\begin{array}{l}\text { - "A yoga class should have less than } 12 \text { students. I would want a class of } 7 \text { to } 8 \\
\text { students only, } 9 \text { people in } 3 \text { rows would be good."(A3) } \\
\text { - "It would be more comfortable with less people in the yoga class. A full class can } \\
\text { not do yoga. You can not control a full class."(C1) }\end{array}$ \\
\hline & b) Short class & $\begin{array}{l}\text { "Short time of yoga in the morning sounds good. I would like to do it for a short } \\
\text { while like } 15 \text { to } 20 \text { minutes rather than for approximately } 40 \text { minutes. Then it would } \\
\text { not be boring.....even for } 3 \text { times a week."(A4) }\end{array}$ \\
\hline & $\begin{array}{l}\text { c) Persistent } \\
\text { class }\end{array}$ & $\begin{array}{l}\text { "Teaching consistently not so much all at once but instead every day. I somehow } \\
\text { think this way will leave a deeper impression"(A1) } \\
\text {. "I think it is important to do it continuously like this. it would be better physically } \\
\text { and mentally if it is consistent,"(A4) }\end{array}$ \\
\hline & $\begin{array}{l}\text { d) Cost and } \\
\text { obligation } \\
\text { to attend }\end{array}$ & $\begin{array}{l}\text { - "Having a cheaper price would attract many students. But if it was free, classmates } \\
\text { would not want to do it. 50,000 won seems reasonable."(A3) } \\
\text {. "I would come if you took attendance. I may be late if I am sick, but I would not miss } \\
\text { the class."(A3) }\end{array}$ \\
\hline
\end{tabular}


Table 5. Representative Quotations of Suggestions for a School-based Yoga Class (Continued)

\begin{tabular}{|c|c|c|}
\hline Categories & Subcategories & Representative quotations \\
\hline \multirow[t]{7}{*}{$\begin{array}{l}\text { Strategies for } \\
\text { promoting } \\
\text { participation }\end{array}$} & $\begin{array}{l}\text { a) Support and } \\
\text { encouragement } \\
\text { by teacher or } \\
\text { classmate }\end{array}$ & $\begin{array}{l}\text { - "I think the atmosphere is really important. Classmate do when people say that it' } s \\
\text { good so let' s do it together."(A4) } \\
\text {. "We are still adolescents; we need to be forced in every aspect. Our class teacher } \\
\text { told us not to do it so I was discouraged by the teacher. I am like this because our } \\
\text { teacher is not a good role model."(A4) }\end{array}$ \\
\hline & $\begin{array}{l}\text { b) Achievement } \\
\text { and challenge }\end{array}$ & $\begin{array}{l}\text { - "Setting a goal and achieving it together."(C1) } \\
\text { - "Yoga should be not too easy. Yoga should be challenging. I would like some } \\
\text { different postures every day."(B3) }\end{array}$ \\
\hline & $\begin{array}{l}\text { c) Yoga } \\
\text { should have a } \\
\text { purpose }\end{array}$ & $\begin{array}{l}\text { - "If you say you will lose weight doing yoga, a lot of students will come...and also if it } \\
\text { is for losing weight or improving concentration."(B3) } \\
\text {. "Doing yoga to get taller and reduce acne by improving the blood circulation rather } \\
\text { than weight loss would attract a lot of boys."(B2) }\end{array}$ \\
\hline & $\begin{array}{l}\text { d) Yoga } \\
\text { should be } \\
\text { charming }\end{array}$ & $\begin{array}{l}\text { "I want the yoga teacher to be pretty. My yoga teacher was really slim, curvy and } \\
\text { pretty, I think that I could be like that."(B3) } \\
\text {. "Showing a case like how a celebrity turned out by doing yoga would really motivate } \\
\text { them. Showing photos of results from after yoga."(C1) }\end{array}$ \\
\hline & $\begin{array}{l}\text { e) Yoga } \\
\text { should be fun }\end{array}$ & $\begin{array}{l}\text { "To gather participants, it should be fun. I hope the program is fun and that is } \\
\text { enough to make me think I want to do it again."(A4) } \\
\text {. "We can have fun together. I think we can enjoy it together. There was a playful } \\
\text { atmosphere and I liked this."(C1) }\end{array}$ \\
\hline & $\begin{array}{l}\text { f) Yoga } \\
\text { should provide } \\
\text { information }\end{array}$ & $\begin{array}{l}\text { - "There is also information about the body. Like in health education class, health } \\
\text { education could be done with it. then, the class was not boring."(C1) } \\
\text {. "It would be better if you tell us about the yoga posture we are going to do today and } \\
\text { what they are good for, and provide more information."(C3) }\end{array}$ \\
\hline & $\begin{array}{l}\text { g) Individual } \\
\text { and tailored } \\
\text { approach }\end{array}$ & $\begin{array}{l}\text { - "I would like individualized class, everybody does a different cat posture."(A1) } \\
\text {. "By doing a physical examination before a yoga class, you could teach him the } \\
\text { movements for his weak parts. So personalized program would be good as new } \\
\text { yoga program."(C3) }\end{array}$ \\
\hline \multirow[t]{2}{*}{$\begin{array}{l}\text { Suggestions for } \\
\text { sustaining } \\
\text { in daily life }\end{array}$} & $\begin{array}{l}\text { a) Simple } \\
\text { and easy }\end{array}$ & $\begin{array}{l}\text { "A way to do it persistently in daily life would be, do it at the desk. It would be nice } \\
\text { if you teach, how to stretch the neck sitting in a bus."(A3) } \\
\text {. "Well, I was busy following instructions and being passive the entire time because I } \\
\text { did not know a lot, So simple and easy yoga is better."(A2) } \\
\text { - "It is easy if you do only one movement because it is what you have been } \\
\text { persistently learning. If it is something you can do easily while sitting, it would be } \\
\text { effective doing it in daily life."(C3) }\end{array}$ \\
\hline & $\begin{array}{l}\text { b) Healthy } \\
\text { habits }\end{array}$ & $\begin{array}{l}\text { "I like to practice yoga frequently even it is for a short time. I think not having } \\
\text { enough time is an excuse. We can get enough time if you save time little by little } \\
\text { from other things. So we should do it every day rather than every other day for some } \\
\text { amount of time. If we remind ourselves and do it every day, it will become a habit } \\
\text { and we will be able to do some stretching that we learned while studying."(A4) } \\
\text {. "Yoga should be done every day if it is for all the students in the school. I think we } \\
\text { should make yoga an everyday habit for our health"(A3) }\end{array}$ \\
\hline
\end{tabular}

\section{DISCUSSION}

This is the first published qualitative study using content analysis on Korean adolescents' experience with yoga class. We identified the motivation for joining a yo- ga class, the perceived benefits after the yoga class, and suggestions for an appropriate school-based yoga class to promote health in adolescents through focused interviews. Although the focus groups were not always conducted in response to the research questions, the resear- 
ch question approach was appropriate for this study because the investigators obtained richer information speaking as the voice of the student on existing benefits and a suitable design for a school-based yoga program than the simple survey method. Such information will be helpful for schools to develop a yoga class for adolescents or for others working to disseminate yoga more broadly throughout society and to make yoga more friendly for high school students as well as to advance our general understanding of yoga.

The first research question assessed the motivations for joining a yoga class. The students choose a yoga class from among after-school exercise programs because yoga was perceived as less tiring than that of soccer or basketball, and they said that the exercise time required the least amount of time for physical activity in their school. In industrialized countries, yoga is offered as a fitness course along with classes such as Pilates and group cycle. ${ }^{1)}$ The most common reasons given for undertaking yoga were to maintain flexibility and promote muscle relaxation in a previous study. ${ }^{7}$ However, although people may adopt yoga as physical exercise, they may discover other aspects, such as yoga's spiritual or philosophical aspects that become more central motivations with continued practice. ${ }^{6}$ The reasons for choosing to do yoga include having a holistic health philosophy or a transformational experience that changes one's world view and wanting greater control over one's own health. ${ }^{5)}$ Our participants reported intrinsic and extrinsic motivations for participating in yoga classes. A small qualitative study found that participants in a yoga intervention for people with or at high risk for diabetes reported continuing to practice for both intrinsic (e.g. feeling that yoga improved their health and energy levels) and extrinsic (e.g. finding that having others in the group reinforced motivation) motivations. ${ }^{10)}$ Therefore, healthcare providers of the school should develop a strategy to enhance intrinsic and extrinsic motivations for joining the yoga class and understand two type of motives in adolescents.

In our study, we identified more benefits than just the expected one of exercise for the body and mind. Most participants reported multi-dimensional benefits. These results are consistent with previous findings in adult populations. ${ }^{10-12,18,27)}$ Unlike adult populations, our participants mentioned remarkably cognitive and social benefit. This could also be a result of the developmental characteristics of adolescence. They reported that the yoga class helped with their academic performance by improving their concentration and reducing fatigue re- lated to sitting a long time while studying as cognitive benefits. These results are consistent with previous findings that students, who practiced yoga for an hour daily in the morning for 7 weeks, performed better academically, and that study also showed that low-stress students performed better than high-stress students in mathematics, science, and social studies. ${ }^{14)}$ Another study found that yoga helped relieve academic stress and improve the overall attitude about school, and many of the yoga techniques that relieve stress were used before tests. ${ }^{13)}$ Therefore, application of yoga classes designed for the balanced development could be useful in adolescents needing encouragement to promote health behaviors.

In addition, most of our participants enjoyed the yoga class, but a negative report about yoga meditation was associated with gender. One boy wanted more active exercise. Although it is hard to generalize the different preferences to yoga by gender because only one male participant gave a negative report in this study, the girls are mentioned that yoga is more intimate than other sports. Not only gender differences in the perception of yoga class but also gender differences in the purpose for participating in yoga classes were seen. In contrast to girls preferring yoga for weight control, a boy mentioned during the interview that he preferred yoga to increase his height. Previous research on yoga use and preference also showed these gender differences. ${ }^{7)} \mathrm{A}$ national survey on yoga reported that the ratio of women among yoga practitioners was $84.2 \%$ in the USA.18) In this study, recruitment of adolescents who experienced yoga was biased towards female participants which is understandably based on this preference.

Most participants including all the girls from the vocational high school were interested in weight loss through yoga practice. Some of the participants mentioned that they continuously reduced their intake of food while taking the yoga class and that practicing yoga supported efforts toward dietary improvements. A study examined the results of a 12-week yoga treatment program for binge eating among a sample of 25 women who were obese. ${ }^{9)}$ The study revealed a positive shift experienced by the women during the program; specifically, the women perceived an overall reduction in the quantity of food they consumed, a decreased eating speed, and an improvement in their food choices throughout the program. ${ }^{9)}$ Yoga practice is associated with improved dietary intake and healthy attitudes toward eating, according to studies among women with varying ages and some with a history of binge eating. ${ }^{9)}$ The efficacy of yo- 
ga to influence eating behaviors and patterns, or other lifestyle factors, merits further investigation. ${ }^{9,11)}$

Additionally, the more moderate levels of stress in the participants was similar to that of usual high school students in Korea. According to the Korean Youth Risk Behavior Web-base Survey 2013, the female adolescents felt a lot of stress evaluated at 51.7\%(in the general high school) and 55\%(in the vocational high school). ${ }^{17}$ Several studies report that various stresses from the uncertainty about the future, going to college, grades on the tests and low physical activity induced by studying all day, no break. ${ }^{15,16)}$ In other studies on yoga for high school student, many have cited stress reduction, and many have used yoga to manage negative emotions such as depression, anxiety, and anger, and some stated that more happiness, calmness, and a sense of refreshment were propagated. ${ }^{12,13)}$ These results suggest that school-based yoga programs may be appropriate for promoting health by focusing on the prevention of negative patterns during the transition of adolescents. In addition, It is important that school-based yoga classes are adopted to meet particular developmental needs and health related conditions.

The participants also offered a lot of suggestions for an appropriate yoga class in their school. Some of the students reported that a yoga class should have a specific purpose such as weight control or physical fitness to encourage participants. Regarding feasibility, the yoga class should be easy and simple in order to be acceptable for general students as mentioned in the focus group. In addition, they strongly suggested that the yoga class be held in a comfortable, clean environment with a quiet atmosphere and they wanted the yoga classroom to be warm, natural and friendly such as the sound of water instead of the traffic noise from the street. In addition, participants reported that a supportive person is essential to sustain yoga practice. Children aged $0 \sim 17$ years, whose parents used complementary and alternative medicine (CAM) were almost five times as likely (23.9\%) to use CAM as children whose parents did not use CAM $(5.1 \%){ }^{5)}$ Since adolescents are still dependent adults, the support of parents and teachers is essential to choose and maintain healthy behavior.

For both adults and children, they were worried about the cost of complementary care as well as conventional care. ${ }^{5)}$ In other study, most participants reported that they would continue to practice yoga if it is offered in school. ${ }^{13)}$ Hence, the cost should taken into account in designing a school-based yoga program. Furthermore, the yoga teacher should adapt a style to meet the devel- opmental and physical needs of students in the yoga class. ${ }^{27)}$ Maintaining yoga practice over time is a challenge similar to that of other forms of lifestyle change. ${ }^{28)}$ Health educators may be able to support maintenance by discussing more specific strategies to promote health behaviors and sustain yoga practice in daily life as a holistic intervention. ${ }^{28)}$ Managing the cause of a poor lifestyle and making an individual understand and enjoy a healthy lifestyle are of utmost importance. ${ }^{29)}$ Yoga was seen as a multidimensional intervention linked to change in all dimensions of human experience, and body awareness seems to be a key mechanism in these changes. ${ }^{1)}$ Future research might consider how to best implement strategies that use these positive qualities of a yoga practice to develop school-based yoga programs with lifestyle modifications and health education.

The limitations of this qualitative include the generalization of these findings and that the participants did not represent the whole Korean adolescent population because this study had only 11 participants recruited by the convenience sampling method from two different types of schools, and they had experiences with a variety of yoga classes. Thus, this diversity in the characteristics of yoga classes can contribute to a rich description about the benefits of yoga and to suggestions for future yoga classes. In addition, this qualitative data were collected retrospectively not with a longitudinal follow-up study to explore the motivations of a past event when they signed up for the yoga class. More research is needed to explore the changing process in the perceptions of the participants with a prospective method over time when participating in a yoga program and the yoga program could be targeted to specific health conditions such as obesity or eating disorders in the adolescents.

\section{CONCLUSION}

Based on the findings from this qualitative study, it is clear that yoga practice is an appealing and beneficial intervention at a physical, psychological, cognitive, and social level as well as a physical exercise for high school students. Yoga may be a practice that could effectively contribute to achieving the World Health Organization's definition of health as a "state of complete physical, mental, and social well-being, and not merely the absence of disease or infirmity." ${ }^{30)}$ Almost all of the participants shared a desire to join another yoga class, again, and they suggested that a supportive, tailored-made, purposeful, attractive yoga class would promote participation. Another finding also described that a simple and 
easy yoga class is more appropriate for school-based yoga programs. Furthermore, yoga practice should result in healthy habits and not just simple exercise, leading to the balanced development of adolescents.

\section{REFERENCES}

1. Cope S. The Wisdom of Yoga. New York: Bantam Dell; 2006.

2. Birdee GS, Legedza AT, Saper RB, Bertisch SM, Eisenberg DM, Phillips RS. Characteristics of yoga users: results of a national survey. J Gen Intern Med. 2008;23(10):1653-8. http://dx.doi.org/10.1007/s11606-008-0735-5

3. National Center for Complementary and Alternative Medicine. Get the fact, yoga for health. [Internet]. Maryland: National Center for Complementary and Alternative Medicine; 2008 May [updated 2013 Jun; cited 2014 Aug 4]. 6 p. Available from: http://nccam.nih.gov/health/yoga/introduction.htm

4. Peregoy JA, Clarke TC, Jones LI, Stussman BJ, Nahin RL. Regional variation in use of complementary health approaches by U.S. adults [Internet]. Hyattsville (MD): National Center for Health Statistics; 2014 Apr [cited 2014 Aug 4]. 1-8 p.(NCHS Data Brief; no. 146). Available from:

http://www.cdc.gov/nchs/data/databriefs/db146.pdf

5. Barnes PM, Bloom B, Nahin RL. Complementary and alternative medicine use among adults and children: United States, 2007 [Internet]. Hyattsville (MD): National Center for Health Statistics; 2008 Dec [cited 2014 Aug 4]. 1-24 p. (National health statistics reports; no. 12) Available from:

http://www.cdc.gov/nchs/data/nhsr/nhsr012.pdf

6. Bussing A, Hedtstuck A, Khalsa SB, Ostermann T, Heusser P. Development of Specific Aspects of Spirituality during a 6Month Intensive Yoga Practice. Evid Based Complement Alternat Med. 2012;2012:981523.

http://dx.doi.org/10.1155/2012/981523

7. Park CL, Cho D, Wortmann JH. The impact of Yoga upon young adult cancer survivors. Complement Ther Clin Pract. 2013;19(2):77-82.

http://dx.doi.org/10.1016/j.ctcp.2012.12.005

8. Tekur P, Nagarathna R, Chametcha S, Hankey A, Nagendra HR. A comprehensive yoga programs improves pain, anxiety and depression in chronic low back pain patients more than exercise: an RCT. Complement Ther Med. 2012;20(3):107-18. http://dx.doi.org/10.1016/j.ctim.2011.12.009

9. McIver S, McGartland M, O'Halloran P. "Overeating is not about the food": women describe their experience of a yoga treatment program for binge eating. Qual Health Res. 2009; 19(9):1234-45. http://dx.doi.org/10.1177/1049732309343954

10. Alexander GK, Innes KE, Brown CJ, Kulbok P, Bourguignon C, Bovbjerg VE, et al. "I could move mountains": adults with or at risk for type 2 diabetes reflect on their experiences with yoga practice. Diabetes Educ. 2010;36(6):965-75. http://dx.doi.org/10.1177/0145721710381802

11. Alexander GK, Innes KE, Selfe TK, Brown CJ. "More than I expected": perceived benefits of yoga practice among older adults at risk for cardiovascular disease. Complement Ther Med. 2013;21(1):14-28. http://dx.doi.org/10.1016/j.ctim.2012.11.001

12. Conboy LA, Noggle JJ, Frey JL, Kudesia RS, Khalsa SB. Qualitative evaluation of a high school yoga program: feasibility and perceived benefits. Explore (NY). 2013;9(3):171-80. http://dx.doi.org/10.1016/j.explore.2013.02.001

13. Noggle JJ, Steiner NJ, Minami T, Khalsa SB. Benefits of yoga for psychosocial well-being in a US high school curriculum: a preliminary randomized controlled trial. J Dev Behav Pediatr. 2012;33(3):193-201.

http://dx.doi.org/10.1097/DBP.0b013e31824afdc4

14. Kauts A, Sharma N. Effect of yoga on academic performance in relation to stress. Int J Yoga. 2009;2(1):39-43. http://dx.doi.org/10.4103/0973-6131.53860

15. White LS. Reducing stress in school-age girls through mindful yoga. J Pediatr Health Care. 2012;26(1):45-56. http://dx.doi.org/10.1016/j.pedhc.2011.01.002

16. Birdee GS, Yeh GY, Wayne PM, Phillips RS, Davis RB, Gardiner P. Clinical applications of yoga for the pediatric population: a systematic review. Acad Pediatr. 2009;9(4):212-20 e1-9. http://dx.doi.org/10.1016/j.acap.2009.04.002

17. Korea Centers for Disease Control and Prevention. [Korea youth risk behavior web-based survey] [Internet]. Chungcheongbuk-do: Korea Centers for Disease Control and Prevention; 2013 Dec 13 [cited 2014 Aug 4]. 20 p. Available from: https://yhs.cdc.go.kr/result/data_view.asp?seq=13\&page=1

18. Ross A, Friedmann E, Bevans M, Thomas S. National survey of yoga practitioners: mental and physical health benefits. Complement Ther Med. 2013;21(4):313-23.

http://dx.doi.org/10.1016/j.ctim.2013.04.001

19. Jung HY. A qualitative study of the influence, psychologically and physically, that yoga, meditation and dance programs may have upon high school students who are also smokers [master's thesis]. Gwangju: Chonnam National University; 2009.

20. Park CL, Riley KE, Bedesin E, Stewart VM. Why practice yoga? Practitioners' motivations for adopting and maintaining yoga practice. J Health Psychol. 2014.

http://dx.doi.org/10.1177/1359105314541314

21. Peterson-Sweeney K. The use of focus groups in pediatric and adolescent research. J Pediatr Health Care. 2005;19(2):104-10. http://dx.doi.org/10.1016/j.pedhc.2004.08.006

22. Morgan DL. Focus group as qualitative research. 2nd ed. Thousand Oaks(CA): Sage Publication; 1997.

23. Morgan DL. Qualitative content analysis: a guide to paths not 
taken. Qual Health Res. 1993;3(1):112-21.

http://dx.doi.org/10.1177/104973239300300107

24. Hsieh HF, Shannon SE. Three approaches to qualitative content analysis. Qual Health Res. 2005;15(9):1277-88. http://dx.doi.org/10.1177/1049732305276687

25. Graneheim UH, Lundman B. Qualitative content analysis in nursing research: concepts, procedures and measures to achieve trustworthiness. Nurse Educ Today. 2004;24(2):10512. http://dx.doi.org/10.1016/j.nedt.2003.10.001

26. Sandelowski M. The problem of rigor in qualitative research. ANS Adv Nurs Sci. 1986;8(3):27-37.

27. Atkinson NL, Permuth-Levine R. Benefits, barriers, and cues to action of yoga practice: a focus group approach. Am J
Health Behav. 2009;33(1):3-14.

28. Ross A, Friedmann E, Bevans M, Thomas S. Frequency of yoga practice predicts health: results of a national survey of yoga practitioners. Evid Based Complement Alternat Med. 2012;2012:983258. http://dx.doi.org/10.1155/2012/983258

29. Yadav RK, Magan D, Mehta N, Sharma R, Mahapatra SC. Efficacy of a short-term yoga-based lifestyle intervention in reducing stress and inflammation: preliminary results. J Altern Complement Med. 2012;18(7):662-7.

http://dx.doi.org/10.1089/acm.2011.0265

30. WHO.int [internet]. Geneva: World Health Organization; c2003. WHO definition of health; [cited 2014 Aug 4] Available from: http://who.int/about/definition/en/print.html 